\title{
Combined analysis of preoperative and postoperative lymphocyte-C-reactive protein ratio precisely predicts outcomes of patients with gastric cancer
}

Kozo Miyatani ( $\sim$ kozo5963@tottori-u.ac.jp )

Tottori University Faculty of Medicine

Shohei Sawata

Tottori University Faculty of Medicine

Masahiro Makinoya

Tottori University Faculty of Medicine

Wataru Miyauchi

Tottori University Faculty of Medicine

Shota Shimizu

Tottori University Faculty of Medicine

Yuji Shishido

Tottori University Faculty of Medicine

Tomoyuki Matsunaga

Tottori University Faculty of Medicine

Manabu Yamamoto

Tottori University Faculty of Medicine

Naruo Tokuyasu

Tottori University Faculty of Medicine

Shuichi Takano

Tottori University Faculty of Medicine

Teruhisa Sakamoto

Tottori University Faculty of Medicine

Toshimichi Hasegawa

Tottori University Faculty of Medicine

Hiroaki Saito

Japanese Red Cross Tottori Hospital

Yoshiyuki Fujiwara

Tottori University Faculty of Medicine 


\section{Research Article}

Keywords: Gastric cancer, LCR, prognosis

Posted Date: February 16th, 2022

DOI: https://doi.org/10.21203/rs.3.rs-1163746/v1

License: (c) (i) This work is licensed under a Creative Commons Attribution 4.0 International License. Read Full License 


\section{Abstract}

Background》 The systemic inflammatory response resulting from the complex interactions between cancer and the host plays an important role in cancer development. Recently, the lymphocyte-C-reactive protein ratio (LCR), which is a hematological and biochemical marker that reflects the systemic inflammatory response and nutritional status, has been reported to be associated with poor survival. Similar results were observed in patients with certain cancer types. However, these studies focused on the preoperative LCR, and thus far, no studies have reported the relationship between postoperative LCR and prognosis in patients with gastric cancer (GC).

Methods $\$ This study enrolled 455 patients with a histopathological diagnosis of gastric adenocarcinoma who underwent curative surgery at our institution between 2005 and 2018. The relationship between both the preoperative and postoperative LCR and the prognosis of patients with GC was retrospectively investigated.

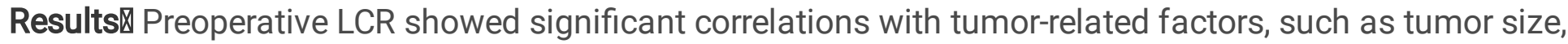
depth of invasion, and lymph node metastasis. By contrast, no correlation was observed between postoperative LCR and tumor-related factors. The 5 year survival rate was significantly worse in patients with low preoperative LCR than in those with high preoperative LCR $(65.4 \%$ vs. $83.9 \%, p<0.0001)$. Similarly, the 5 year survival rate was also significantly worse in patients with low postoperative LCR than in those with high postoperative LCR $(67.0 \%$ vs. $84.1 \%, p<0.0001)$. Furthermore, combination analysis of the preoperative and postoperative LCR revealed that the prognosis of patients with both low preoperative and postoperative LCR was worse in patients with GC (5 year survival rate was $52.0 \%$ ). A multivariate analysis indicated that a low preoperative and postoperative LCR and age and lymph node metastasis were independent prognostic indicators.

Conclusions $\rrbracket$ The combination of preoperative and postoperative LCR appears to be useful in predicting the prognosis of patients with GC.

\section{Background}

Worldwide, over 1,000,000 new gastric cancers (GC) cases and 783,000 GC deaths were estimated to have occurred in 2018 , and thus, GC ranks as the fifth most frequently diagnosed cancer and the third leading cause of cancer mortality [1]. Therefore, determining the postoperative prognosis of patients with $\mathrm{GC}$ is crucial. When considering the prognosis of patients with malignant tumors, the TNM-classification system [2], which considers tumor-related factors and accurately reflects prognosis, has been widely used. Several studies of patients with GC have demonstrated that the depth of invasion and presence or absence of lymph node metastasis may be considered the most important prognostic factors [3, 4]. On the contrary, over the past few years, many researchers have suggested that the outcomes of patients with cancer are determined not only by tumor-related factors but also by patient-related factors, including inflammation, nutrition, and immune status. Recently, many studies have shown the prognostic 
significance of certain host-related factors based on systemic inflammation, such as the neutrophillymphocyte ratio (NLR), the platelet-lymphocyte ratio (PLR), and the Glasgow Prognostic Score (GPS), which are independent prognostic factors of survival in patients with GC [5-7]. Additionally, a chronic systemic inflammatory response is clearly associated with the progressive nutritional decline seen in patients with cancer and their subsequent poor outcomes [8]. For example, the prognostic nutritional index (PNI) was reported as a prognostic indicator in patients after radical resection for GC [9]. However, most of these reports explored the preoperative status, and few studies have been conducted to investigate the prognostic impact of the postoperative status. Moreover, we reported that markers of postoperative inflammation and nutrition, such as the postoperative NLR [10] and the postoperative PNI [11], are also related to the prognosis of patients with GC. Recently, Okugawa et al. reported the preoperative LCR as a novel nutrition-inflammation marker that predicts prognosis and the risk of postoperative surgical site infection in patients with GC [12]. Additionally, several studies have shown that the LCR can predict oncological outcomes in some types of malignancies [13-15]. However, no reports have been published on the relationship between postoperative LCR, which may represent the systemic inflammatory response and the nutritional status after tumor removal, and the prognosis in patients with GC. The aim of the present study was to determine the prognostic significance of preoperative and postoperative LCR in patients with GC.

\section{Materials And Methods}

\section{Patients}

This study enrolled 455 patients with a histopathological diagnosis of gastric adenocarcinoma who underwent curative surgery at Tottori University Hospital between 2005 and 2018. The data were collected retrospectively. Clinicopathological findings were generally determined according to the 15th edition of the Japanese Classification of Gastric Carcinoma [16]. All patients underwent either distal partial, proximal partial or total gastrectomy with regional lymph node dissection. We collected data from blood tests conducted preoperatively and 1 month postoperatively. The LCR was then calculated as follows: total lymphocyte count $(\mathrm{LC})$ (number/ $\mu \mathrm{L}) / \mathrm{CRP}$ level $(\mathrm{mg} / \mathrm{dL})$. Postoperative complications were considered grade 2 or higher according to the Clavien-Dindo classification. Patients were periodically checked for early recurrence by diagnostic imaging (chest X-ray, double-contrast barium meal study, upper gastrointestinal endoscopy, ultrasonography, and computed tomography). Causes of death were determined by reviewing the medical records, which included laboratory data, ultrasonography, computed tomography, scintigrams, peritoneal punctures, and laparotomies, or by direct inquiry with family members. In some cases, postmortems were conducted to determine the cause of death. Institutional review board of Tottori University Hospital approved this study and waived informed consent.

\section{Statistical analysis}


For statistical analyses, chi-square and Fisher's exact probability tests were used to compare the distribution of individual variables between patient groups. Differences between the two groups were evaluated using the Mann-Whitney U test. Survival curves were calculated according to the KaplanMeier method. Differences between survival curves were examined using the log-rank test. We conducted a multivariate analysis of factors considered to predict overall survival (OS) using a Cox proportional hazards model. $P<0.05$ was considered significant. All statistical analyses were conducted with EZR (Saitama Medical Center, Jichi Medical University, Saitama, Japan), which is a graphical user interface for R (The R Foundation for Statistical Computing, Vienna, Austria). More precisely, EZR is a modified version of $\mathrm{R}$ commander designed to add statistical functions frequently used in biostatistics.

\section{Results}

The mean preoperative and postoperative LCR values were 39,650 (range: 190-347,900) and 41,487 (range: 132-333,900), respectively. Table 1 shows the correlations between the preoperative and postoperative LCR and clinicopathological variables in patients with GC. Statistically significant correlations were found between low preoperative LCR and age $(p<0.0001)$, gender $(p=0.001)$, tumor size $(p=0.002)$, depth of invasion $(p=0.006)$, lymph node metastasis $(p=0.013)$, lymphatic involvement $(p=0.006)$, vascular involvement $(p=0.025)$, lymphadenectomy $(p=0.003)$, and postoperative complications $(p=0.012)$. By contrast, statistically significant correlations were found between low postoperative LCR and age $(p<0.0001)$, gender $(p=0.0007)$, CEA level $(p=0.045)$, and postoperative complications $(p<0.0001)$.

We next investigated the prognostic significance of preoperative and postoperative LCR in patients with GC. Receiver-operating characteristic (ROC) analysis of the OS status showed that the optimal cutoff values of the pre and postoperative LCR were 23,800 (area under the curve [AUC], 0.639; $p<0.0001$; Fig. 1a) and 13,033 (AUC, $0.630 ; p<0.0001$; Fig. 1b), respectively. Patients were divided accordingly as follows: pre-LCR $\geq 23,800$ (pre-LCR ${ }^{\text {High }}, n=315$ ), pre-LCR $<23,800$ (pre-LCR ${ }^{\text {Low }}, n=140$ ), post-LCR $\geq 13033$ (post-LCR ${ }^{\text {High }}, \mathrm{n}=294$ ), and post-LCR $<13,033$ (post-LCR ${ }^{\text {Low }}, \mathrm{n}=161$ ). The 5 year OS rates were significantly related to pre-LCR (pre-LCR ${ }^{\text {High. }} 83.9 \%$; pre-LCR ${ }^{\text {Low. }} 65.4 \% ; p<0.0001$; Fig. 2a) and post-LCR (post-LCR ${ }^{\text {High. }}$ 84.1\%; post-LCR ${ }^{\text {Low. }} 67.0 \% ; p<0.0001$; Fig. 2b).

Overall, 232, 83, 62, and 78 patients were in the pre-LCR ${ }^{H i g h}$ and post-LCR ${ }^{H i g h}$, pre-LCR ${ }^{\text {High }}$ and post$\mathrm{LCR}^{\mathrm{Low}}$, pre-LCR ${ }^{\mathrm{Low}}$ and post-LCR ${ }^{\text {High }}$, and pre-LCR ${ }^{\mathrm{Low}}$, and post-LCR ${ }^{\mathrm{Low}}$ groups, respectively. The 5 year OS rates were $84.8 \%$ and $81.2 \%$ for patients with pre-LCR ${ }^{\text {High }}$ and post-LCR ${ }^{\text {High }}$ and for patients with pre$\mathrm{LCR}^{\text {High }}$ and post-LCR ${ }^{\mathrm{Low}}$, respectively, but this difference was not significant ( $p=0.205$; Fig. $3 a$ ). On the contrary, the 5 year OS rates were $81.6 \%$ and $52.0 \%$ for patients with pre-LCR ${ }^{\text {Low }}$ and post-LCR ${ }^{\text {High }}$ and for patients with pre-LCR ${ }^{\mathrm{Low}}$ and post-LCR ${ }^{\mathrm{Low}}$, respectively, and this difference was significant $(p=0.0004$; Fig. 3b). 
The patients were then divided into groups $A$ (those with pre-LCR ${ }^{H i g h}$ and post-LCR ${ }^{H i g h}$ ), $B$ (those with either pre-LCR ${ }^{\text {High }}$ and post-LCR ${ }^{\text {Low }}$ or pre-LCR ${ }^{\text {Low }}$ and post-LCR ${ }^{\text {High }}$ ), and $C$ (those with pre-LCR ${ }^{\text {Low }}$ and post-LCR ${ }^{\text {Low }}$ ). Group B contained two subgroups because the 5 year OS rates were almost the same (81.2\% in patients with pre-LCR ${ }^{H i g h}$ and post-LCR ${ }^{\text {Low }}$ and $81.6 \%$ in those with pre-LCR ${ }^{\text {Low }}$ and post$L_{C R}{ }^{\text {High }}$ ), as mentioned above. The patients in groups $A, B$, and $C$ were assigned 0,1 , and 2 , respectively. ROC curves were constructed for the OS status, and then the AUC values were compared to assess the discrimination ability of the preoperative LCR, postoperative LCR, and the combination of the preoperative and postoperative LCR (Fig. 4). Among the three prognostic scores, the combination of the preoperative and postoperative LCR had the highest AUC value (0.647), followed by the preoperative LCR (AUC 0.639) and the postoperative LCR (AUC 0.630). These findings indicate that the combination of preoperative and postoperative LCR was more useful for predicting the prognosis of patients with GC than either the preoperative or postoperative LCR alone. The overall 5 year survival rates were $84.8 \%, 81.3 \%$, and $52.0 \%$ for groups $A, B$, and $C$, respectively, and these differences were significant $(p<0.0001$; Fig. 5a). Moreover, the relapse-free 5 year survival rates were $84.7 \%, 78.5 \%$, and $50.8 \%$ for groups $A, B$, and $C$, respectively, and these differences were significant ( $p<0.0001$; Fig. 5b).

We conducted a univariate analysis of the clinicopathological factors considered to be prognostic predictors of OS in patients with GC. The univariate analysis identified age, tumor size, depth of invasion, lymph node metastasis, lymphatic involvement, venous involvement, postoperative complications, and the combination of preoperative and postoperative LCR as prognostic factors. Then, in the multivariate analysis, we included parameters significant at $p<0.05$ in the univariate analysis. The multivariate analysis revealed that the combined preoperative and postoperative LCR, age, and lymph node metastasis were independent prognostic indicators of OS (Table 2). Additionally, similar results were observed in the univariate and multivariate analyses of prognostic factors for relapse-free survival (RFS) (Table 3).

\section{Discussion}

There have been substantial discussions about the importance of the systemic inflammation that results from the complex interactions between cancer and host during disease development $[8,17]$. Furthermore, accumulating evidence has demonstrated the association between poor nutritional status and impaired immunity in patients with cancer $[18,19]$. In relation to these findings, LCR has been developed as a nutrition-inflammation marker and serves as a prognostic biomarker in patients with GC [12]. However, it is still unclear how the LCR is associated with the prognosis of patients with cancer. With respect to the association between LC and the prognosis of patients with cancer, lymphocytes, which include $\mathrm{CD} 4^{+}$and $\mathrm{CD}^{+} \mathrm{T}$ cells, natural killer (NK) cells, NKT cells, gamma-delta T cells, and B cells, have been reported to play an important role in tumor immunity in the host. In this connection, functional impairment of lymphocytes and decreased lymphocyte counts have been reported in various types of cancers [20,21], and this is likely associated with impairment of antitumor immunity. Furthermore, Saito et al. reported that low preoperative and postoperative LC values were significantly associated with poor prognosis of 
patients with GC [22]. Regarding the association between CRP and the prognosis of patients with cancer, CRP is the most common marker used to evaluate the magnitude of systemic inflammation because of its sensitivity, specificity, and reproducibility of analysis in hospital laboratories. Additionally, CRP is an acute-phase reactant synthesized predominantly in the liver [23] that is regulated by proinflammatory cytokines, particularly IL-6 [24]. Kim et al. reported that in GC, serum IL-6 levels were positively correlated with CRP levels and were also correlated with the TNM stage; the CRP level served as a poor prognostic factor for disease recurrence and OS [25]. Considering these findings, the LCR is likely to be associated with tumor progression and the prognosis of patients with cancer.

In the present study, we demonstrated that preoperative LCR was significantly associated with tumorrelated factors, such as tumor size, depth of invasion, and lymph node metastasis, among others, and that a low preoperative LCR was related to an unfavorable prognosis. These findings are consistent with those of a previous report [12] and could be considered consequences of complex host-tumor interactions that play a pivotal role in GC development. On the contrary, a low postoperative LCR was significantly associated with poor prognosis despite the lack of association between postoperative LCR and tumor-related factors. Interestingly, similar results have also been reported in previous studies, which found that other postoperative markers, such as the postoperative NLR and PNI, served as poor prognostic factors despite the lack of correlation between these markers and tumor-related factors [10, $11,26,27]$. Naturally, the postoperative markers were not associated with tumor-related factors considering the tumors had been removed. However, the detailed mechanism by which postoperative markers, including the postoperative LCR, are associated with the prognosis of patients with cancer remains unclear. Presumably, one possible mechanism is the effect of micro metastatic residual tumor cells that cannot be eradicated by surgery. Complete surgical resection of the primary tumor is performed to achieve a cure for locally advanced GC, but even after complete resection, tumor recurrence can still occur [28]. The cause of postoperative tumor recurrence is considered an effect of micro metastasis, which exists outside the surgical field and gradually multiplies to affect host survival. Some studies have claimed that the immunological response against infectious postoperative complications enhances the viability of micro metastatic residual tumor cells after surgery [29-31]. Additionally, noninfectious postoperative complications, such as anastomotic stenosis, lymphorrhea, and bleeding, induce malnutrition and cause lymphopenia, which results in immunosuppression [10]. Through the above mechanisms, micro metastatic residual tumor cells secrete various proinflammatory cytokines and negative immune modulators; these triggers decreased postoperative LC and increased postoperative CRP, which might be responsible for a low postoperative LCR. Therefore, a low postoperative LCR is associated with a poor prognosis. Actually, according to the present study, low preoperative and postoperative LCR was significantly associated with the occurrence of postoperative complications and was an independent prognostic indicator of OS and RFS.

With respect to the prognostic utility of preoperative LCR in patients with GC, as reported previously, our results indicated that low preoperative LCR was significantly associated with a poor prognosis. Similarly, low postoperative LCR was also significantly associated with a poor prognosis, which was a novel finding. Considering these results, it can be presumed that perioperative low LCR, namely, a continuous 
systemic inflammatory response and suppression of the entire immune system after surgery of a patient with cancer, creates a favorable environment for micro metastatic growth. Thus, we hypothesized that the combination of the preoperative and postoperative LCR might be more useful in the prediction of the prognosis of patients with GC than either the preoperative LCR or the postoperative LCR alone. Actually, considering the result of the comparison of the AUC value for the OS status, the combination of the preoperative and postoperative LCR more precisely predicted a poor prognosis than either the preoperative or postoperative LCR alone. Additionally, the multivariate analysis revealed that the combination of the low preoperative and postoperative LCR was an independent prognostic indicator of OS. Taken together, our findings show that both the postoperative status and preoperative status are important when considering the prognosis.

Over the past few years, many researchers have suggested that the number of circulating tumor cells (CTCs) could be a prognostic indicator in patients with cancer, such as breast cancer, small-cell lung cancer, colorectal cancer, and GC [32-35]. However, the techniques by which CTCs are detected are often complicated and unsuitable for routine clinical settings. Conversely, inflammation and nutrition markers including perioperative LCR are easy to measure and are useful for prognostic prediction. Moreover, Zheng et al. demonstrated that preoperative markers, such as the systemic immune-inflammation index (SII), NLR, PLR, and PNI, are robust predictors of CTCs in patients with GC undergoing tumor resection [36]. A further study on whether postoperative markers including postoperative LCR are associated with CTC detection in patients with GC who have undergone tumor resection or not should be conducted.

This study also has some limitations. First, some bias was present because of the study's retrospective nature. Second, we measured the LCR 1 month after surgery and considered that value to be the postoperative LCR; however, the appropriate timing of when the postoperative LCR should be measured remains unclear. Third, all the patients enrolled in this study were from a single institution in Japan. To overcome these limitations, a large-scale, prospective randomized controlled trial is needed.

\section{Conclusion}

The combination of preoperative and postoperative LCR appears to be useful to predict the prognosis of patients with GC. Since perioperative assessment of LC and CRP is readily available, noninvasive, and easy to perform, measurement of the preoperative and postoperative LCR may be useful as a clinical biological tool in routine clinical settings.

\section{Abbreviations}

LCR: lymphocyte-C-reactive protein ratio; GC: gastric cancer; NLR: neutrophil-lymphocyte ratio; PLR: platelet-lymphocyte ratio; GPS: Glasgow Prognostic Score; PNI: prognostic nutritional index; LC: lymphocyte count; OS: overall survival; RFS: relapse-free survival; NK: natural killer; CTC: circulating tumor cell; SIl: systemic immune-inflammation index 


\section{Declarations}

\section{Ethics approval and consent to participate}

All procedures performed in this study involving human participants were in accordance with the ethical standards of the institutional review board of the ethics committee, the national research committee, and the 1964 Declaration of Helsinki and its later amendments. The institutional review board of our institution approved the study (Institutional review board of Tottori University Hospital, number 20A243) and waived the need for informed consent.

\section{Consent for publication}

Not applicable.

\section{Availability of data and materials}

The datasets used and analyzed during the current study are not publicly available due to their containing information that could compromise the privacy of research participants but are available from the corresponding author on reasonable request.

\section{Competing interests}

The authors declare that they have no competing interests.

\section{Funding}

The authors have no financial support to declare.

\section{Authors' contributions}

Study conception: KM; Study design: KM; Data acquisition: SS, MM, WM, SS, YS, TM, and MY; Quality control of data and algorithms: NT and ST; Data analysis and interpretation: TS and TH; Statistical analysis: KM; Manuscript preparation: KM; Manuscript editing: HS; Manuscript review: YF; Final approval of the article: all authors. All authors read and approved the final manuscript.

\section{Acknowledgements}

The authors would like to thank Enago (www.enago.jp) for the English language review. 


\section{Author information}

1 Division of Gastrointestinal and Pediatric Surgery, Department of Surgery, School of Medicine, Tottori University Faculty of Medicine, Yonago 683-8504, Japan.

2 Department of Surgery, Japanese Red Cross Tottori Hospital, Tottori 680-8517, Japan.

\section{References}

1. Bray F, Ferlay J, Soerjomataram I, Siegel RL, Torre LA, Jemal A. Global cancer statistics 2018 : GLOBOCAN estimates of incidence and mortality worldwide for 36 cancers in 185 countries. CA Cancer J Clin. 2018;68:394-424.

2. J.D.Brierley MKG, C.Wittekind: TNM classification of malignant tumors. 8th ed. Wiley 2017.

3. Bozzetti F, Bonfanti G, Morabito A, Bufalino R, Menotti V, Andreola S, et al. A multifactorial approach for the prognosis of patients with carcinoma of the stomach after curative resection. Surg Gynecol Obstet. 1986;162:229-34.

4. Maruyama K. The most important prognostic factors for gastric cancer patients. Scand J Gastroenterol. 1987;22:63-8.

5. Shimada H, Takiguchi N, Kainuma O, Soda H, Ikeda A, Cho A, et al. High preoperative neutrophillymphocyte ratio predicts poor survival in patients with gastric cancer. Gastric CancerOffJInt Gastric Cancer Assoc.Jpn Gastric Cancer Assoc. 2010;13:170-6.

6. Jiang X, Hiki N, Nunobe S, Kumagai K, Kubota T, Aikou S, et al. Prognostic importance of the inflammation-based Glasgow prognostic score in patients with gastric cancer. BrJCancer. 2012;107:275-9.

7. Jiang N, Deng JY, Liu Y, Ke B, Liu HG, Liang H. The role of preoperative neutrophil-lymphocyte and platelet-lymphocyte ratio in patients after radical resection for gastric cancer. Biomarkers : biochemical indicators of exposure, response, and susceptibility to chemicals. 2014;19:444-51.

8. McMillan DC. Systemic inflammation, nutritional status and survival in patients with cancer. Curr Opin Clin Nutr Metab Care. 2009;12:223-6.

9. Nozoe T, Ninomiya M, Maeda T, Matsukuma A, Nakashima H, Ezaki T. Prognostic nutritional index: a tool to predict the biological aggressiveness of gastric carcinoma. SurgToday. 2010;40:440-3.

10. Miyatani K, Saito H, Kono Y, Murakami Y, Kuroda H, Matsunaga $T$, et al. Combined analysis of the preand postoperative neutrophil-lymphocyte ratio predicts the outcomes of patients with gastric cancer. SurgToday. 2018;48:300-7.

11. Murakami Y, Saito H, Kono Y, Shishido Y, Kuroda H, Matsunaga T, et al. Combined analysis of the preoperative and postoperative prognostic nutritional index offers a precise predictor of the prognosis of patients with gastric cancer. SurgToday. 2018;48:395-403.

12. Okugawa Y, Toiyama Y, Yamamoto A, Shigemori T, Ichikawa T, Yin C, et al. Lymphocyte-to-C-reactive protein ratio and score are clinically feasible nutrition-inflammation markers of outcome in patients 
with gastric cancer. Clin Nutr. 2020;39:1209-17.

13. Okugawa Y, Toiyama Y, Yamamoto A, Shigemori T, Ide S, Kitajima T, et al. Lymphocyte-C-reactive protein ratio as promising new marker for predicting surgical and oncological outcomes in colorectal cancer. Ann Surg. 2020;272:342-51.

14. He Y, Gong R, Peng KW, Liu LZ, Sun LY, Wang HY. Lymphocyte-to-C-reactive protein ratio is a potential new prognostic biomarker for patients with lung cancer. Biomark Med. 2020;14:717-26.

15. Noguchi D, Kuriyama N, Nakagawa Y, Maeda K, Shinkai T, Gyoten K, et al. The prognostic impact of lymphocyte-to-C-reactive protein score in patients undergoing surgical resection for intrahepatic cholangiocarcinoma: A comparative study of major representative inflammatory / immunonutritional markers. PLOS ONE. 2021;16:e0245946.

16. The 15th edition $₫ 3$ rd English edition $₫$ of the Japanese classification of gastric carcinoma.

17. Roxburgh CS, McMillan DC. Role of systemic inflammatory response in predicting survival in patients with primary operable cancer. Future Oncol. 2010;6:149-63.

18. Song GM, Tian X, Liang H, Yi LJ, Zhou JG, Zeng Z, et al. Role of enteral immunonutrition in patients undergoing surgery for gastric cancer: A systematic review and meta-analysis of randomized controlled trials. Medicine (Baltimore). 2015;94:e1311.

19. Ryan AM, Reynolds JV, Healy L, Byrne M, Moore J, Brannelly N, et al. Enteral nutrition enriched with eicosapentaenoic acid (EPA) preserves lean body mass following esophageal cancer surgery: results of a double-blinded randomized controlled trial. Ann Surg. 2009;249:355-63.

20. Matsuzaki J, Gnjatic S, Mhawech-Fauceglia P, Beck A, Miller A, Tsuji T, et al. Tumor-infiltrating NYESO-1-specific CD8+ T cells are negatively regulated by LAG-3 and PD-1 in human ovarian cancer. Proc Natl Acad Sci U S A. 2010;107:7875-80.

21. Takahashi A, Kono K, Amemiya H, lizuka H, Fujii H, Matsumoto Y. Elevated caspase-3 activity in peripheral blood $T$ cells coexists with increased degree of T-cell apoptosis and down-regulation of TCR zeta molecules in patients with gastric cancer. Clin Cancer Res. 2001;7:74-80.

22. Saito H, Kono Y, Murakami Y, Shishido Y, Kuroda H, Yamamoto M, et al. Prognostic significance of pre- and postoperative lymphocyte counts in patients with gastric cancer. Dig Surg. 2019;36:137-43.

23. Hurlimann J, Thorbecke GJ, Hochwald GM. The liver as the site of C-reactive protein formation. J Exp Med. 1966;123:365-78.

24. Morris-Stiff G, Gomez D, Prasad KR. C-reactive protein in liver cancer surgery. Eur J Surg Oncol. 2008;34:727-9.

25. Kim DK, Oh SY, Kwon HC, Lee S, Kwon KA, Kim BG, et al. Clinical significances of preoperative serum interleukin-6 and C-reactive protein level in operable gastric cancer. BMC cancer. 2009;9:155.

26. Shibutani M, Maeda K, Nagahara H, Ohtani H, Iseki Y, Ikeya T, et al. The prognostic significance of a postoperative systemic inflammatory response in patients with colorectal cancer. World J Surg Oncol. 2015;13:194. 
27. Shibutani M, Maeda $K$, Nagahara $H$, Ohtani $H$, Iseki $Y$, Ikeya $T$, et al. The prognostic significance of the postoperative prognostic nutritional index in patients with colorectal cancer. BMC Cancer. 2015;15:521.

28. Sasako M. Principles of surgical treatment for curable gastric cancer. J Clin Oncol. 2003;21:274s-5s.

29. Miki C, Tanaka K, Inoue Y, Araki T, Ohi M, Mohri Y, et al. Perioperative host-tumor inflammatory interactions: a potential trigger for disease recurrence following a curative resection for colorectal cancer. SurgToday. 2008;38:579-84.

30. Mynster T, Christensen IJ, Moesgaard F, Nielsen HJ. Effects of the combination of blood transfusion and postoperative infectious complications on prognosis after surgery for colorectal cancer. Danish RANX05 Colorectal Cancer Study Group. Br J Surg. 2000;87:1553-62.

31. Tsujimoto H, Ichikura T, Ono S, Sugasawa H, Hiraki S, Sakamoto N, et al. Impact of postoperative infection on long-term survival after potentially curative resection for gastric cancer. Ann Surg Oncol. 2009;16:311-8.

32. Cohen SJ, Punt CJ, lannotti N, Saidman BH, Sabbath KD, Gabrail NY, et al. Relationship of circulating tumor cells to tumor response, progression-free survival, and overall survival in patients with metastatic colorectal cancer. J Clin Oncol. 2008;26:3213-21.

33. Giuliano M, Giordano A, Jackson S, Hess KR, De Giorgi U, Mego M, et al. Circulating tumor cells as prognostic and predictive markers in metastatic breast cancer patients receiving first-line systemic treatment. Breast Cancer Res. 2011;13:R67.

34. Igawa S, Gohda K, Fukui T, Ryuge S, Otani S, Masago A, et al. Circulating tumor cells as a prognostic factor in patients with small cell lung cancer. Oncol Lett. 2014;7:1469-73.

35. Inoue M, Otsuka K, Shibata H. Circulating tumor cell count as a biomarker of a specific gastric cancer subgroup characterized by bone metastasis and/or disseminated intravascular coagulation - an early indicator of chemotherapeutic response. Oncol Lett. 2016;11:1294-8.

36. Zheng L, Zou K, Yang C, Chen F, Guo T, Xiong B. Inflammation-based indexes and clinicopathologic features are strong predictive values of preoperative circulating tumor cell detection in gastric cancer patients. Clin Transl Oncol. 2017;19:1125-32.

\section{Tables}

Table 1

Relationships between the preoperative and postoperative LCR and clinicopathological variables in patients with gastric cancer 
Pre-LCR

Age

$<75 \rrbracket n=298 \rrbracket$

$\geq 75 \rrbracket n=157 \rrbracket$

Gender

Male $₫ n=332 \rrbracket$

Female $₫ n=123 \rrbracket$

Tumor size

$<4 \mathrm{~cm} \rrbracket \mathrm{n}=277 \rrbracket$

$\geq 4 \mathrm{~cm} \otimes \mathrm{n}=178 \rrbracket$

Differentiation

Differentiated $₫ n=261 \rrbracket$

Poorly differentiated $₫ n=194 \rrbracket$

Depth of invasion

$\mathrm{T} 1 \rrbracket \mathrm{n}=287 \rrbracket$

$\mathrm{T} 2 / 3 / 4 \rrbracket \mathrm{n}=168 \rrbracket$

Lymph node metastasis

Absent $\nabla n=325 \rrbracket$

Present $₫ n=130 \rrbracket$

Lymphatic involvement

Absent $₫ n=199 \rrbracket$

Present $\bigotimes n=256 \rrbracket$

Vascular involvement

Absent $₫ n=229 \rrbracket$

Present $₫ n=226 \rrbracket$

Stage

I $₫ \mathrm{n}=307 \rrbracket$

II/III $₫ n=148 \rrbracket$

CEA $p$ value Post-LCR

$\llbracket 0.0001$

$45508 \pm 52948$

$28532 \pm 36722$

$34784 \pm 44367$

$52786 \pm 56686$

0.002

$44611 \pm 53185$

$31930 \pm 39383$

0.421

$37479 \pm 47514$

$42571 \pm 50015$

0.006

$43386 \pm 48998$

$33268 \pm 47398$

0.013

$42652 \pm 49065$

$32147 \pm 46790$

0.006

$46685 \pm 53217$

$34182 \pm 44032$

0.025

$45495 \pm 53053$

$33728 \pm 42956$

0.063

$41935 \pm 48565$

$34912 \pm 48517$
$49304 \pm 55861$

$26652 \pm 35818$

0.0007

$36508 \pm 45063$

$54928 \pm 62532$

0.294

$43890 \pm 53136$

$37749 \pm 47319$

0.289

$38031 \pm 46889$

$46137 \pm 55790$

0.55

$43027 \pm 52705$

$38858 \pm 47912$

0.582

$42533 \pm 51809$

$38874 \pm 48923$

0.183

$44284 \pm 51689$

$39314 \pm 50405$

0.203

$42729 \pm 49083$

$40230 \pm 52901$

0.681

$42928 \pm 52670$

$38500 \pm 47296$ $<0.001$ 


\begin{tabular}{|c|c|c|c|c|}
\hline$<5 \mathrm{ng} / \mathrm{mL} \otimes \mathrm{n}=396 \rrbracket$ & $41296 \pm 50745$ & & $43062 \pm 51413$ & \\
\hline$\geq 5 \mathrm{ng} / \mathrm{mL} \otimes \mathrm{n}=59 \rrbracket$ & $28604 \pm 28539$ & & $30920 \pm 46980$ & \\
\hline CA19-9 & & 0.285 & & 0.571 \\
\hline 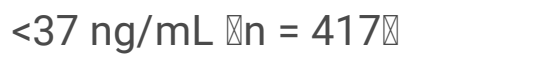 & $40670 \pm 50059$ & & $42401 \pm 52312$ & \\
\hline 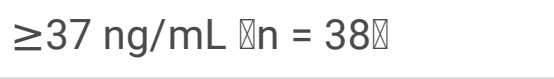 & $28463 \pm 25994$ & & $31464 \pm 31666$ & \\
\hline Gastrectomy & & 0.516 & & 0.796 \\
\hline 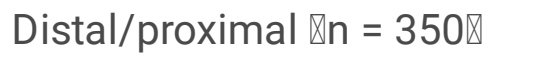 & $40438 \pm 49015$ & & $41099 \pm 49566$ & \\
\hline Total $\varangle \mathrm{n}=105 \rrbracket$ & $37026 \pm 47358$ & & $42783 \pm 55645$ & \\
\hline Lymphadenectomy & & 0.003 & & 0.335 \\
\hline $\mathrm{D} 0 / \mathrm{D} 1 / \mathrm{D} 1+\bigotimes \mathrm{n}=315 \rrbracket$ & $43373 \pm 49489$ & & $42477 \pm 50033$ & \\
\hline$D 2 \triangle n=140 \rrbracket$ & $31274 \pm 45632$ & & $39262 \pm 53148$ & \\
\hline Operation time & & 0.092 & & 0.878 \\
\hline$<$ Median $₫ n=227 \rrbracket$ & $36386 \pm 44043$ & & $42071 \pm 50172$ & \\
\hline$\geq$ Median $\bigotimes n=228 \rrbracket$ & $42900 \pm 52658$ & & $40907 \pm 51865$ & \\
\hline Postoperative complications & & 0.012 & & $\bowtie 0.0001$ \\
\hline Absent $\bigotimes n=314 \rrbracket$ & $43607 \pm 52275$ & & $46013 \pm 51861$ & \\
\hline Present $₫ n=141 \rrbracket$ & $30839 \pm 37936$ & & $31411 \pm 47591$ & \\
\hline
\end{tabular}

All results are expressed as the mean \pm standard deviation

CEA carcinoembryonic antigen, CA19-9 carbohydrate antigen 19-9

The median operation time was $324 \mathrm{~min}$

Postoperative complications were considered grade 2 or higher according to the Clavien-Dindo classification

\section{Table 2}

Univariate and multivariate analyses of prognostic factors for overall survival in patients with gastric cancer 


\begin{tabular}{|c|c|c|c|c|c|c|}
\hline & $p$ value & $\mathrm{HR}^{\mathrm{d}}$ & $95 \% \mathrm{Cl}^{\mathrm{e}}$ & $p$ value & $\mathrm{HR}$ & $95 \% \mathrm{Cl}$ \\
\hline Age $(\geq 75$ vs. $<75)$ & 0.0004 & 1.996 & $\begin{array}{l}1.361- \\
2.926\end{array}$ & 0.002 & 1.929 & $\begin{array}{l}1.285- \\
2.896\end{array}$ \\
\hline Gender (Male vs. Female) & 0.100 & 1.489 & $\begin{array}{l}0.931- \\
2.381\end{array}$ & & & \\
\hline Tumor size ( $\geq 4$ vs. $<4$ ) & 0.0037 & 1.760 & $\begin{array}{l}1.202- \\
2.576\end{array}$ & 0.307 & 1.247 & $\begin{array}{l}0.816- \\
1.905\end{array}$ \\
\hline $\begin{array}{l}\text { Differentiation (Undifferentiated vs. } \\
\text { Differentiated)a }\end{array}$ & 0.393 & 1.181 & $\begin{array}{l}0.806- \\
1.730\end{array}$ & & & \\
\hline Depth of invasion (T2-4 vs. T1) & $<0.0001$ & 2.279 & $\begin{array}{l}1.552- \\
3.347\end{array}$ & 0.698 & 1.111 & $\begin{array}{l}0.653- \\
1.888\end{array}$ \\
\hline $\begin{array}{l}\text { Lymph node metastasis (Present vs. } \\
\text { Absent) }\end{array}$ & $<0.0001$ & 2.897 & $\begin{array}{l}1.978- \\
4.244\end{array}$ & 0.0001 & 2.476 & $\begin{array}{l}1.564- \\
3.919\end{array}$ \\
\hline $\begin{array}{l}\text { Lymphatic involvement (Present vs. } \\
\text { Absent) }\end{array}$ & $<0.0001$ & 2.458 & $\begin{array}{l}1.587- \\
3.807\end{array}$ & 0.518 & 0.793 & $\begin{array}{l}0.393- \\
1.601\end{array}$ \\
\hline $\begin{array}{l}\text { Venous involvement (Present vs. } \\
\text { Absent) }\end{array}$ & $<0.0001$ & 2.814 & $\begin{array}{l}1.844- \\
4.297\end{array}$ & 0.058 & 1.908 & $\begin{array}{l}0.978- \\
3.723\end{array}$ \\
\hline $\begin{array}{l}\text { Postoperative complications (Present } \\
\text { vs. Absent) }{ }^{c}\end{array}$ & 0.002 & 1.844 & $\begin{array}{l}1.251- \\
2.717\end{array}$ & 0.072 & 1.446 & $\begin{array}{l}0.967- \\
2.163\end{array}$ \\
\hline \multirow{2}{*}{$\begin{array}{l}\text { Combination of pre and postoperative } \\
\text { LCR } \\
\text { pre- and post-LCR }{ }^{\text {Low }} \text { vs. pre- or post- } \\
\text { LCR }^{\text {High }}\end{array}$} & & & & & & \\
\hline & $<0.0001$ & 2.810 & $\begin{array}{l}1.747- \\
4.519\end{array}$ & $<0.0001$ & & $\begin{array}{l}1.719- \\
4.496\end{array}$ \\
\hline $\begin{array}{l}\text { pre- and post-LCR }{ }^{\text {Low }} \text { vs. pre- and } \\
\text { post-LCR }{ }^{\text {High }}\end{array}$ & $<0.0001$ & 3.831 & $\begin{array}{l}2.434- \\
6.031\end{array}$ & $<0.0001$ & 3.023 & $\begin{array}{l}1.893- \\
4.829\end{array}$ \\
\hline
\end{tabular}

a Histology: Differentiated, papillary, or tubular adenocarcinoma; undifferentiated, poorly differentiated or mucinous adenocarcinoma, or signet ring cell carcinoma

${ }^{b}$ Depth of invasion: T1, tumor invasion of the lamina propria or submucosa; T2, tumor invasion of the muscularis propria or subserosa; T3, tumor penetration of the serosa; T4, tumor invasion of adjacent organs

${ }^{\mathrm{c}}$ Postoperative complications were considered grade 2 or higher according to the Clavien-Dindo classification
d HR, hazard ratio
${ }^{\text {e }} \mathrm{CI}$, confidence interval 
Table 3

Univariate and multivariate analyses of prognostic factors for relapse-free survival in patients with gastric cancer 


\begin{tabular}{|c|c|c|c|c|c|c|}
\hline & $p$ value & $\mathrm{HR}^{\mathrm{d}}$ & $95 \% \mathrm{Cl}^{\mathrm{e}}$ & $p$ value & $H R$ & $95 \% \mathrm{Cl}$ \\
\hline Age ( $\geq 75$ vs. $<75)$ & 0.0026 & 1.777 & $\begin{array}{l}1.222- \\
2.585\end{array}$ & 0.011 & 1.669 & $\begin{array}{l}1.124- \\
2.477\end{array}$ \\
\hline Gender (Male vs. Female) & 0.092 & 1.483 & $\begin{array}{l}0.937- \\
2.347\end{array}$ & & & \\
\hline Tumor size ( $\geq 4$ vs. $<4$ ) & 0.003 & 1.759 & $\begin{array}{l}1.212- \\
2.553\end{array}$ & 0.495 & 1.156 & $\begin{array}{l}0.763- \\
1.750\end{array}$ \\
\hline $\begin{array}{l}\text { Differentiation (Undifferentiated vs. } \\
\text { Differentiated) }\end{array}$ & 0.321 & 1.208 & $\begin{array}{l}0.832- \\
1.754\end{array}$ & & & \\
\hline Depth of invasion (T2-4 vs. T1) ${ }^{b}$ & $<0.0001$ & 2.536 & $\begin{array}{l}1.741- \\
3.694\end{array}$ & 0.453 & 1.220 & $\begin{array}{l}0.726- \\
2.051\end{array}$ \\
\hline $\begin{array}{l}\text { Lymph node metastasis (Present vs. } \\
\text { Absent) }\end{array}$ & $<0.0001$ & 3.388 & $\begin{array}{l}2.333- \\
4.920\end{array}$ & $<0.0001$ & 2.757 & $\begin{array}{l}1.756- \\
4.329\end{array}$ \\
\hline $\begin{array}{l}\text { Lymphatic involvement (Present vs. } \\
\text { Absent) }\end{array}$ & $<0.0001$ & 2.602 & $\begin{array}{l}1.695- \\
3.994\end{array}$ & 0.422 & 0.756 & $\begin{array}{l}0.382- \\
1.497\end{array}$ \\
\hline $\begin{array}{l}\text { Venous involvement (Present vs. } \\
\text { Absent) }\end{array}$ & $<0.0001$ & 3.006 & $\begin{array}{l}1.985- \\
4.553\end{array}$ & 0.041 & 1.960 & $\begin{array}{l}1.028- \\
3.735\end{array}$ \\
\hline $\begin{array}{l}\text { Postoperative complication (Present } \\
\text { vs. Absent) }{ }^{c}\end{array}$ & 0.002 & 1.816 & $\begin{array}{l}1.244- \\
2.652\end{array}$ & 0.047 & 1.487 & $\begin{array}{l}1.006- \\
2.199\end{array}$ \\
\hline $\begin{array}{l}\text { Combination of pre and postoperative } \\
\text { LCR } \\
\text { pre- and post-LCR }{ }^{\text {Low }} \text { vs. pre- or post- } \\
\text { LCR }^{\text {High }}\end{array}$ & 0.0001 & 2.474 & $\begin{array}{l}1.566- \\
3.906\end{array}$ & 0.0002 & 2.398 & $\begin{array}{l}1.511- \\
3.805\end{array}$ \\
\hline $\begin{array}{l}\mathrm{LCR}^{\mathrm{High}} \\
\text { pre- and post-LCR }{ }^{\text {Low }} \text { vs. pre- and } \\
\text { post-LCR }\end{array}$ & $<0.0001$ & 3.845 & $\begin{array}{l}2.450- \\
6.031\end{array}$ & $<0.0001$ & 3.120 & $\begin{array}{l}1.961- \\
4.965\end{array}$ \\
\hline
\end{tabular}

a Histology: Differentiated, papillary, or tubular adenocarcinoma; undifferentiated, poorly differentiated or mucinous adenocarcinoma, or signet ring cell carcinoma

b Depth of invasion: T1, tumor invasion of the lamina propria or submucosa; T2, tumor invasion of the muscularis propria or subserosa; T3, tumor penetration of the serosa; T4, tumor invasion of adjacent organs

${ }^{\mathrm{c}}$ Postoperative complications were considered grade 2 or higher according to the Clavien-Dindo classification

${ }^{\mathrm{d}} \mathrm{HR}$, hazard ratio

${ }^{\mathrm{e}} \mathrm{CI}$, confidence interval 
Figures

Miyatani et al. Figure 1 (a

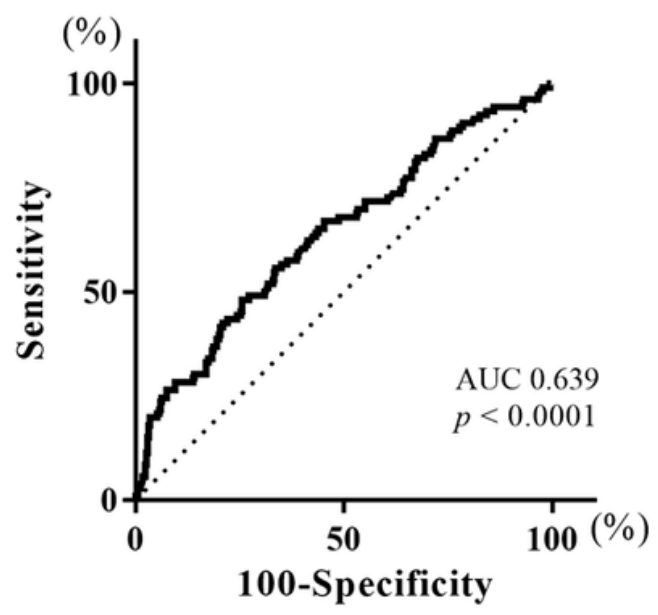

Miyatani et al. Figure $1(b)$

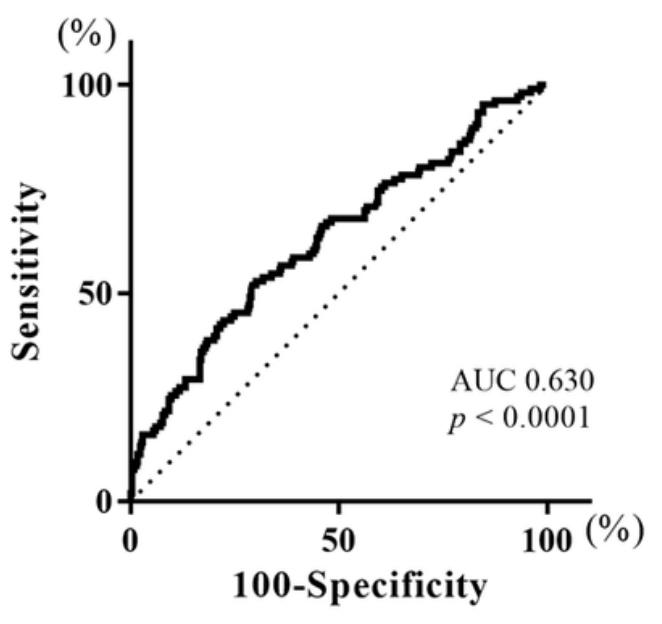

Figure 1

Receiver-operating characteristic (ROC) curve shows the optimal prognostic cutoff for (a) preoperative LCR, (b) postoperative LCR for the overall survival status.

Miyatani et al. Figure 2 (a)

Miyatani et al. Figure $2(b)$
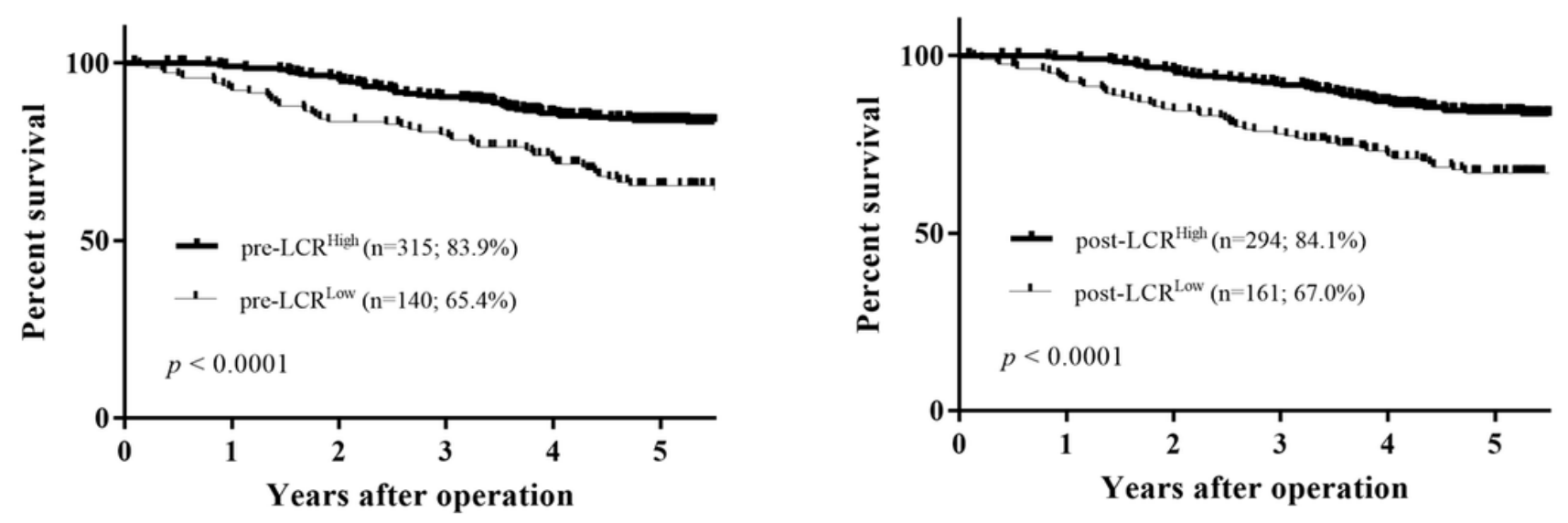

Figure 2 
Survival curves according to the preoperative LCR. (a) The 5 year survival rate was significantly worse in patients with pre-LCR ${ }^{\text {Low }}$ than in those with pre-LCR ${ }^{H i g h}(65.4 \%$ vs. $83.9 \%, p<0.0001)$. (b) Survival curves according to the postoperative LCR. The 5 year survival rate was significantly worse in patients with post$\mathrm{LCR}^{\mathrm{Low}}$ than in those with post-LCR ${ }^{\mathrm{High}}(67.0 \%$ vs. $84.1 \%, p<0.0001)$.

\section{Miyatani et al. Figure 3 (a)}

Miyatani et al. Figure 3 (b)
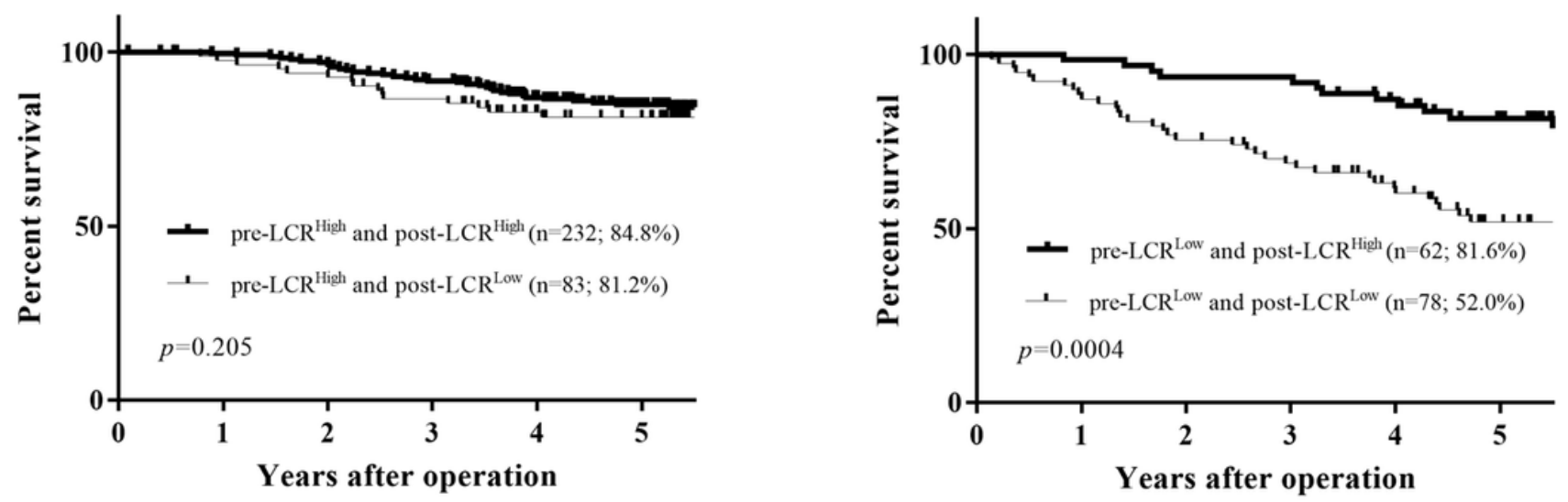

\section{Figure 3}

Survival curves according to the postoperative LCR of patients with pre-LCR ${ }^{\text {High }}$ (a) and those with pre$\mathrm{LCR}^{\mathrm{Low}}(\mathrm{b})$. The 5 year survival among patients with pre-LCR ${ }^{\text {High }}$ and post-LCR ${ }^{\text {High }}$ and among those with pre-LCR ${ }^{\text {High }}$ and post-LCR ${ }^{\text {Low }}$ did not differ significantly $(84.8 \%$ vs. $81.2 \%, p=0.205)$. On the contrary, the 5 year survival rate was significantly worse in patients with pre-LCR ${ }^{\mathrm{Low}}$ and post-LCR ${ }^{\mathrm{Low}}$ than in those with pre-LCR ${ }^{\text {Low }}$ and post-LCR ${ }^{\text {High }}(52.0 \%$ vs. $81.6 \%, p<0.0001)$. 


\section{Miyatani et al. Figure 4}

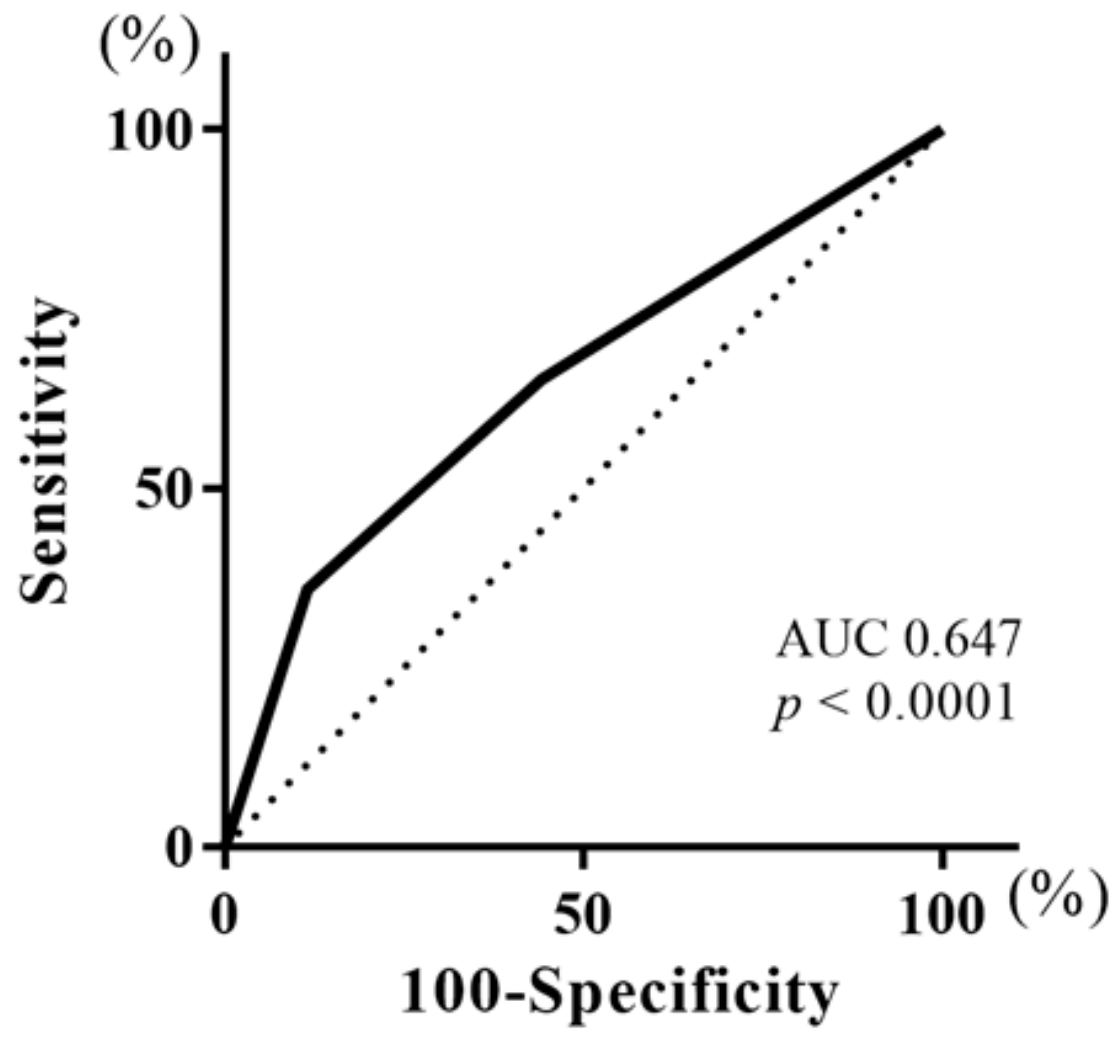

Figure 4

Receiver-operating characteristic (ROC) curve shows the optimal prognostic cutoff for the combination of the preoperative and postoperative LCR for overall survival status. 

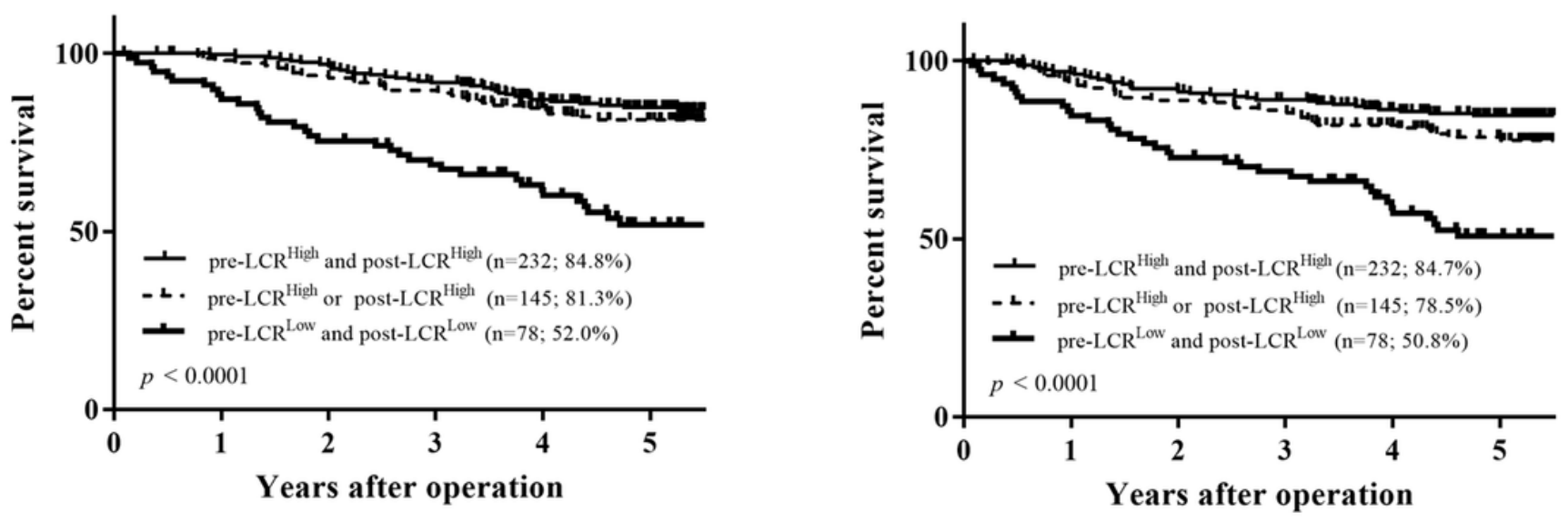

Figure 5

Survival curves according to the combination of pre and postoperative LCR.

(a) The overall 5 year survival rates were $84.8 \%, 81.3 \%$, and $52.0 \%$ in patients with both pre-LCR ${ }^{H i g h}$ and post-LCR ${ }^{\text {High }}$, either pre-LCR ${ }^{H i g h}$ or post-LCR ${ }^{H i g h}$, and both pre-LCR ${ }^{\text {Low }}$ and post-LCR ${ }^{\text {Low }}$, respectively, and the difference was statistically significant $(p<0.0001)$. (b) The relapse-free 5 year survival rates were $84.7 \%, 78.5 \%$, and $50.8 \%$ in patients with both pre-LCR ${ }^{\text {High }}$ and post-LCR ${ }^{\text {High }}$, either pre-LCR ${ }^{\text {High }}$ or post$\mathrm{LCR}^{\text {High }}$, and both pre-LCR ${ }^{\mathrm{Low}}$ and post-LCR ${ }^{\mathrm{Low}}$, respectively, and the difference was statistically significant $(p<0.0001)$. 